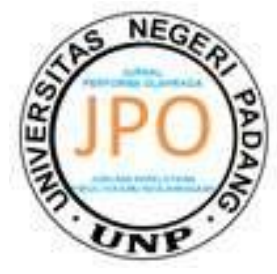

\title{
FAKTOR PENYEBAB KURANGNYA MINAT SISWI SMP 08 KOTA SAWAHLUNTO TERHADAP OLAHRAGA WUSHU
}

\author{
Nurmalina ${ }^{1}$, Hermanzoni ${ }^{2}$ \\ ${ }^{1}$ Fakultas Ilmu Keolahragaan, Universitas Negeri Padang, Inonesia \\ ${ }^{2}$ Universitas Negeri Jakarta, Indonesia.
}

\section{Informasi Artikel}

Diterima 2020-11-23

Direvisi 2021-07-14

Dipublikasikan 2021-08-31

\section{Keyword:}

Interest

Wushu

\begin{abstract}
The problen in this research $\mathrm{u}$ the interest SMP 08 kota sawahlunto student in Wushu.the purpose of this study was to determine the causes of SMP 08 Kota Sawahlunto students to be less interested in Wushu. This study uses qualitative research with descritive methods.This research produces descriptive data in the form of written or spoken words from people and observed behavior. the data colection techniques used were observation, interviews and documentation. This Research was conucted from July to August 2020 at SMP 08 Sawahunto City, Luminday village district Barangin. The population in this study were 76 of all female student of the population in this The were student of SMP 08 Kota Sawahlunto. Sampling using proportional random sampling amounted to 15 students of SMP 08 Kota Sawahlunto. Bases on the results of the resecarch ,the causesbof the lack of asking students for Wushu consisted of two factor two ; 1) external factor and 2) internal factor. Eksternal Factor, a) Infrastructure (27\%), b) Distance (13\%), c) Hard Wushu sports (20\%), d) Parents (27\%), e) Trainers (27\%). Internal factors, a) Pain (7\%), b) Lack of confidence (7\%), c) Doubt (7\%), d) Experience (7\%)
\end{abstract}

(c) 2020 The Authors. Published by Universitas Negeri Padang.

This is an open access article under the CC BY-NC-SA license (https://creativecommons.org/licenses/by-nc-sa/4.0/

Penulis Korespondensi:

Nurmalina

Universitas Negeri Padang

Email: nurmalina7163@gmail.com

\section{PENDAHULUAN}

Ilmu dan teknologi menyebabkan kemajuan dalam perubahan yang cepat berbagai tatanan kehidupan manusia(Ridwan \& Irawan,2018).Olahraga telah terdapat pada semua aspek kehidupan, seperti perekonomian, pendidikan dan lain sebagainya (Juliandra \& Yendrizal, 2018).Olahraga sangat berperan dalam peningkatan kemampuan bangsa dalam melaksanankan sistem pembangunan yang bertingkat (Soniawan\& Irawan, 2018). Hal ini dapat dilihat semakin banyak masyarakat yang melakukan olahraga sebagai bentuk gaya hidup. Rajin berolahraga pasti terbukti membuat badan tetap segar, fit, bugar dan sehat serta siap menghadapi kegiatan seharihari (Anggraini\& Alnedral,2019). Sebuah aktivitas menggunakan fisik yang apabila dilakukan secara rutin dapat menjaga kebugaran tubuh serta meningkatkan kinerja tubuh merupakan olahraga menurut (Haryanto, 2019). Bermacam cabang olahraga yang ada pada zaman sekarang ini, semua bertujuan untuk mempertahankan agar tubuh tetap dalam kondisi prima agar prestasi yang diinginkan dapat terwujud (Haryanto \& Welis, 2019). Olahraga tidak hanya dapat menyehatkan tubuh melainkan berpengaruh terhadap prestasi anak dalam olahraga pendidikan, seseorang boleh memilih cabang-cabang olahraga sesuai dengan bakat dan minat mereka berjenjang pendidikan untuk mengembangkan, mendorong,dan membina potensi jasmani dan 
rohani seseorang. Untuk meningkatkan prestasi maksimal dalam olahraga dibutuhkan latihan fisik, teknik, taktik dan mental (Sin, 2016).

Meningkatkan prestasi olahraga berprestasi bagi atlet yang berbakat, dapat dilihat dari proses latihan secara bertahap yang memiliki program terpadu bertujuan untuk mengembangkan olahraga prestasi (Wahyudi\& Donie, 2019). Olahraga bisa dijadikan wadah untuk berprestasi sehingga bisa mengharumkan nama daerah bahkan negara (Milia\& Aziz,2020).Tertuang dalam UU No 3 Tahun 2005 Bab VII Pasal 25 Ayat 3 Tentang sistem keolahragaan pembinaan pengmbangan olahraga pendidikan berbunyi pembinaan dan pengembangan olahraga pendidikan pada semua jenjang pendidikan memberi kebebasan kepada peserta didik untuk melakukan kegiatan olahraga sesuai dengan bakat an mainat. Pembinaan olahraga bertujuan mengembangkan kualitas hidup masyarakat sehingga secara konsisten perlu menempatkan olahraga sebagai integral dari pembangunan (Mardela, dkk, 2019). Pendidikan merupakan usaha sadar yang dilakukan oleh keluarga, masyarakat an pemerintah, melalui kegiatan pengajaran, bimbingan dan latihan, yang berlangsung di sekolah dan diluar sekolah sepanjang hayat untuk mempersiapkan peserta didik agar dapat memainkan peranan dalam berbagai lingkungan hidup secara tepat di masa yang akan datang (Afandi \& Khamidi, 2018).

Berdasarkan pendapat di atas dijelaskan bahwa pengembangan dan pembinaan olahraga pendidikan pada semua anak-anak bangsa bebas memilih cabang-cabang olahraga sesuai dengan kemampuan dan minat tentang cabang olahraga yang diminati. Aktivitas yang wajib dilakukan setiap orang demi menjaga kebugaran dan kesehatan tubuhnya salah satunya dengan berolahraga (Setiawandkk, 2018).Pada zaman ini olahraga menjadi sebuah kebutuhan yang sangat diminati semua kalangan. Boleh dikatakan sampai saat ini olahraga telah memberikan kontribusi yang sangat positif dan nyata bagi peningkatan kinerja masyarakat dalam melakukan aktivitas. Salah satu cabang olahraga yang dimaksud olahraga Wushu.

Olahraga beladiri yang berasal dari Negara Cina adalah cabang olahraga wushu (Ma, X., Sun, W., Lu, A., Ma, P., \& Jiang, C. (2017). Wushu mencakup semua jenis beladiri cina (Kuan\& Roy, 2007). Olahraga ini adalah seni berperang dab bela diri dengan menggunakan metode pukulan,tendangan, lemparan, jepitan dan memakai gerakkan yang dasari dengan gerkkan tubuh manusia dalam berlatih, untuk mengali potensi terpendam dari tubuh manusia serta melatih keterampilan dalam menggunakan senjata tradisional (Novita, 2014). Seiring waktu Wushu terus berkembang dan disempurnkan. Wushu sekarang terbentuk sebagai seni, latihan kesehatan, latihan bela diri praktis, maupun sara pendisiplinan diri (Setyawati, 2014). Setiap tahun kurangnya peminat atau peserta yang mengikuti Wushu(Ulum, 2013).

Berdasarkan hasil observasi dan data yang didapatkan dilapangan dapat disimpulkan bahwasanya siswa SMP 08 kota Sawahlunto kurang berminat terhadap olahraga Wushu, karena jumlah atlet sampai sekarang hanya berjumlah 16 orang yang terdiri dari 2 putri dan 14 putra.Kecenderungan seseorang terhadap sesuatu yang mereka sukai di sebut dengan minat (Maidarman, 2020). Rasa, lebih suka dan rasa ketertarikan pada suatu hal atau aktivitas adalah minat disertai dengan motivasi dimana motivasi dorongan yang kuat untuk berhasil, dimana individu terfokus untuk mengejar prestasi dari pada imbalan terhadap keberhasilan, seseorang juga bersemangat untuk melakukan sesuatu yang lebih baik (Hermanzoni, 2018). Minat didasari dari penenrimaan akan sesuatu hubungan diri sendiri dengan sesuatu di luar diri. Semakin besar minat, maka semakin kuat atau dekat hubungan tersebut (Nastuti \& Sarwiyono, 2019). Minat didorong oleh faktor yang berasal dari alam diri seseorang (Iskandar, 2017).minat siswa terhadap kondisi seseorang memusatkan perhatian pada objek tertentu dengan perasaan nyaman, sehingga atlet tersebut mampu membuat dirinya termotivasi dan terdorong untuk tetap berada pada keadaan tersebut (Bangun, 2019). Kecenderungan minat sangat dipengaruhi dari faktorfaktor internal atau eksternal sehingga sangat berpengaruh dalam minat siswa terhadap cabang olahraga Wushu (De meester et al, 2014). Berdasarkan permasalahan diatas kurangnya minat siswa terdapat beberpa faktor penyebab kurangnya minat dapat ditentukan olahraga Wushu. Dalam mencari faktor penyebab kurangnya minat dapat ditentukan dari faktor-faktor yang telah ditentukan, sehingga dapat ditentukan memalui pilihan terbanyak dalam sebuah mayoritas siswa (Hudayah \& Winarni, 2014).

Dari uraian diatas dapat diketahui bahwa faktor penyebab kurangnya minat sangat beragam dan hasil observasi yang telah dilaksanakan oleh peneliti bahwa minat siswa di dalam 
lingkungan sekolah tersebut sangatlah kurang dan tidak bisa efektif sehingga perlu dilakukan penelitian untuk mencari faktor penyebab yang paling dominan dalam kurangnya minat terhadap olahraga Wushu di SMPN 08 Kota Sawahlunto.

\section{METODE}

Penelitian yang digunakan adalah penelitian kualitatif dengan metode deskriftif pendekatan yang digunakan adalah yang digunakan adalah pendekatan fenomenologi yang kemudian diolah dan dialnalisis untuk mengambil kesimpulan (Maksum, 2012). Populasi dari penelitian ini adalah siswa perempuan dari kelas 1 sampai kelas 3 SMP 08 Kota Sawahlunto. Penelitian ini dilaksanakan di SMP 08 tepatnya berada di desa Lumindai Kec. Barangin Kota Sawahlunto pada tanggal 27 juli - 20 agustus 2020. Cara pemgambilan sampel pada penelitian ini adalah Proportional Random Sampling. Jumlah populasi 337 siswa-siswi, dan jumlah sampel 18 siswi.

Intrument penelitian yang digunakan dalam mengukur nilai variabel yang ditelit menggunakan wawancara .Dibawah ini adalah angket soal wawancara yang akan dilakukan.

Tabel 1. Soal Wawancara

\begin{tabular}{|c|c|}
\hline Soal angket wawancara & Jawaban \\
\hline $\begin{array}{l}\text { Sudah pernahkah anda dengar } \\
\text { olahraga } W u s h u, \text { jelaskan? }\end{array}$ & \\
\hline $\begin{array}{l}\text { Apakah anda tertarik dengan } \\
\text { olahraga ini,jika tertarik atau tidak } \\
\text { tertarik jelaskan? }\end{array}$ & \\
\hline
\end{tabular}

Teknik pengambilan data dalam penelitian ini meliputi observasi, wawancara, serta dokumentasi.Mengumpulkan data melalui observasi di SMP 08 Kota Sawahlunto, untuk wawancara diambil sampel penelitian yaitu perwakian dari setiap siswa tentang tanggapan mengenai Wushu yang ada di SMP 08 Kota Sawahlunto, serta melakukan dokumentasi pada saat siswa melaksanakan latihan wushu.

\section{HASIL DAN PEMBAHASAN}

\section{Hasil Penelitian}

Hasil penelitian dengan wawancara yang telah dilakukan kepada siswi SMP 08 Kota Sawahlunto, bahwa faktor yang menyebabkan rendahnya minat siswi terhadap olahraga Wushu.

Tabel 2. Faktor Internal dan Eksternal Penyebab Rendahnya Minat Siswi terhadap Olahraga Wushu

\begin{tabular}{|c|l|c|}
\hline No & \multicolumn{1}{|c|}{ Uraian } & Persentase siswa \\
\hline 1 & Sarana dan Prasarana & $27 \%$ \\
\hline 2 & Jarak & $13 \%$ \\
\hline 3 & $\begin{array}{l}\text { Olahraga Wushu cukup } \\
\text { keras }\end{array}$ & $20 \%$ \\
\hline 4 & Orangtua & $27 \%$ \\
\hline 5 & Pelatih & $27 \%$ \\
\hline 6 & Sakit & $7 \%$ \\
\hline 7 & Kurang Percaya Diri & $7 \%$ \\
\hline 8 & Ragu-Ragu & $7 \%$ \\
\hline 9 & Pengalaman & $7 \%$ \\
\hline
\end{tabular}




\begin{tabular}{|c|c|c|c|}
\hline \multirow[t]{12}{*}{ Tabel 3. Hasil Penelitian } & No & Faktor internal & Persentase \\
\hline & No & Faktor Internal & Persentase \\
\hline & 1 & Sakit & $7 \%$ \\
\hline & 2 & $\begin{array}{l}\text { Kurang percaya } \\
\text { diri }\end{array}$ & $7 \%$ \\
\hline & 3 & Ragu-ragu & $7 \%$ \\
\hline & 4 & Pengalaman & $7 \%$ \\
\hline & No & Faktor eksternal & persentase \\
\hline & 1 & Sarana prasarana & $27 \%$ \\
\hline & 2 & Jarak & $13 \%$ \\
\hline & 3 & $\begin{array}{l}\text { Olahraga Wushu } \\
\text { keras }\end{array}$ & $20 \%$ \\
\hline & 4 & Orang tua & $27 \%$ \\
\hline & 5 & Pelatih & $27 \%$ \\
\hline
\end{tabular}

Berdasarkan tabel diatas siswi dipengaruhi oleh faktor yaitu internal dan eksternal. Pada faktor internal siswi merasa sakit ketika melakukan olahraga Wushu dan merasa kurang percaya dan ragu-ragu untuk mengikuti olahraga ini serta kurang nya pengalaman dalam cabang olahraga ini. Sedangkan untuk faktor eksternal siswi disebabkan karena sarana dan prasarana yang tidak memadai, jarak yang cukup jauh pada saat pergi latihan Wushu, olahraga Wushu yang cukup keras, orang tua dan pelatih.

Dari pemaparan tersebut menunjukkan bahwa siswi lebih dipengaruhi oleh faktor eksternal hal ini di buktikan dari 15 siswi yang sudah diwawancarai terdapat 3 orang siswi yang terpengaruh pada faktor internal sedangkan 12 orang siswi terpengaruh ada faktor eksternal.

\section{Pembahasan}

\section{Sarana dan Prasarana}

Sarana dan prasarana olahraga merupakan salah satu pendukung yang terdiri dari berbagai segala bentuk jenis peralatan dan tempat berbentuk bangunan yang digunakan dalam memenuhi prasarana yang di tetapkan untuk pelaksanaan program olahraga (Chan, 2020). Berdasarkan pengamatan selama ini peneliti termasuk atlet Wushu Kota Sawahlunto kondisi sarana dan prasarana yang di lihat di tempat latihan kurang memadai. Jumlah alat yang digunakan masih sedikit, sarung tinju 3 pasang, pecing pad 1 pasang dan matras 20 kotak, sedangkan dalam latihan setidaknya alat yang digunakan seharusnya cukup banyak misalkan 4 sarung tinju, 2 pecing pad dan juga ada pecing buat kaki agar lebih menarik atlet-atlet baru. Pelatih seharusnya juga memiliki metode dalam latihan yang baik dengan sarana yang dimiliki namun yang terjadi pelatih belum mampu untuk menggunakan alat yang ada dengan sebaik-baiknya.

Atlet masih banyak diam dibandingkan bergerak karena kekurangan alat dalam proses latihan. Sarana dan prasarana merupakan unsur yang sangat menunjang unutk menarik atlet-atlet baru untuk mengikuti latihan. Dalam hasil wawancara siswi banyak mengatakan faktor penyebab kurang tertarik dalam olahraga Wushu 27\% dari jumlah anak yang diwawancara.

\section{Jarak}

Dilihat dari observasi jarak tempat tinggal ke tempat latihan Wushu di SMP 08 Kota Sawahlunto lumayan jauh, kondisi lingkungan yang kurang memadai jaln yang belum stabil dan siswi masih banyak berjalan kaki dibandingkan memakai kendaraan, kira-kira jarak dari sekolah ke tempat tinggal berkisar $5 \mathrm{~km}$. Jalan yang dilalui masih berupa jalan setapak. Wawancara yang telah dilakukan menyimpulkan bahwa kurangnya minat untuk mengikuti olahraga Wushu adalah jauhnya jarak yang ditempuh untuk mengikuti latihan yaitu sebesar 13\% dari total keseluruhan anak yang diwawancarai. 


\section{Olahraga Wushu termasuk Olahraga Keras}

Olahraga Wushu adalah olahraga beladiri yang terdiri dari teknik pukulan, tendangan, bantingan dan tangkisan dimana olahraga ini sangat memerlukan kondisi fisik yang bagus tetapi dari observasi yang telah terjadi di tempat latihan program latihan yang dibuat pelatih tidak sesuai dengan kadar atlet, sehingga sebagian atlet merasa program latihan terlalu berat. Olahraga yang baik adalah terprogram sesuai dengan kebutuhan seseorang (Donie, Lesmana\& Hermanzoni, 2018). Dengan program latihan yang tersusun dan terprogram dengan baik dapat mengembangkan kondisi fisik atlet sehingga prestasi yang diharapkan dapat dicapai dengan baik (Aulia, 2018).

Dari wawancara yang telah dilakukan siswi menjawab faktor tentang rendahnya minat siswi mengikuti olahraga Wushu dengan kategori olahraga Wushu termasuk olahraga keras sebanyak $27 \%$ dari total keseluruhan anak yang di wawancarai.

\section{Masyarakat, Orang tua dan Teman Sebaya}

Orang tua juga sangat berpengaruh terhadap minat seseorang, dimana olahraga Wushu belum terlalu tau oleh masyarakat sehingga orang tua menganggap olahraga ini keras. Faktor penyebab kurangnya pemahaman orang tua dan masyarakat terhadap olahraga Wushu.

Orang tua adalah motivasi pertama bagi mereka agar dapat percaya diri dalam berinteraksi dengan lingkungannya, ketika anak tidak memperoleh rasa kepercayaan diri dari orang tua, maka hal tersebut dapat mematikan bakat dan kemampuan anak yang seharusnya ada namun tidak bisa di ekspresikan karena rasa percaya diri mereka yang hilang. Kepercayaan diri merupakan variabel terpenting yang terkait dengan olahraga (Besharat, M. A., \& Pourbohlool, S, 2011). Dapat disimpulkan bahwa salah satu kesuksesan anak yaitu dari dukungan seseorang dalam mengembangkan bakat dan minat sesuai keahlian atau skil yang mereka punya.

Berdasarkan hasil wawancara dan observasi beberapa faktor yang terkait dalam olahrgaa Wushu anak menjawab $27 \%$ faktor orang tua, membantu orang tua $13 \%$, kurang percaya diri $2 \%$ dan ragu-ragu $2 \%$.

\section{Pengalaman}

Pengalaman juga sangat berpengaruh dalam minat seseorang. Jika seseorang termotivasi oleh stimulasi pengalaman maka akan berpartisipasi kedalam suatu aktivitas (Van Heerden, C. H, 2014). Dalam wawancara yang peneliti lakukan didapatkan bahwa siswi sangat takut melihat orang berkelahi jadi tidak ingin ikut dalam olahraga beladiri. Siswi juga mengalami pengalaman pernah melihat orangtua berkelahi dengan orang lain sehingga menyebabkan mereka takut untuk mengikuti olahraga ini. Total persentase yang didapatkan kurang nya minat olahraga ini sebesar $2 \%$.

\section{KESIMPULAN}

Berdasarkan hasil wawancara dan observasi yang dikaitkan, menghasilkan bahwa minat siswi SMP 08 Kota Sawahlunto terhadap olahraga Wushu terdiri dari faktor internal dan eksternal.Sesuatu yang membuat individu berminat dari diri seseorang merupakan faktor internal dari penelitian adalah sakit, kurang percaya diri, ragu-ragu serta pengalaman yang pernah dirasakan siswi. Sedangkan faktor eksternal yang mempengaruhi kurangnya minat siswi untuk mengikuti olahraga Wushu yaitu orangtua, sarana dan prasarana, jarak, Wushu termasuk olahraga yang keras dan pelatih.

Siswi SMP 08 Kota Sawahlunto sangat menyadari bahwa olahraga Wushu adalah olahraga beladiri yang baik bagi dirinya, selain menyehatkan tubuh dan bermanfaat bagi dirinya untuk menjaga diri dari hal yang tidak diinginkan dan Wushu ini sangat berpeluang besar bagi siswi dalam meraih prestasi karena olahraga ini masih langka dibandingkan dengan cabang-cabang olahraga lainnya. 


\section{DAFTAR PUSTAKA}

Anggaraini, S., \& ALnedral, A. (2019). Hubungan Kebugaran Jasmani Terhadap Kecerdasan Emosional Atlet Pencak Silat. Jurnal JPDO, 2(1), 114-118.

Aulia, Y. (2018). Pengaruh Bentuk Latihan Smash Terhadap Kemampuan Smash pada Atlet Bola voli M3C Pesisir Selatan. Performa, 3(02), 139-139.

Bangun, S. Y. (2019).Peran Pelatih Olahraga Ektrakurikuler Dalam Mengembangkan Bakat dan Minat Olahraga Pada Peserta Didik. JURNAL PRESTASI, 2(4), 29-37.

Besharat, M. A., \& Pourbohlool, S. (2011). Moerating effects of self-cinfidence and sporth selfefficacyon the relationship between competitiv anxietyand sporth performace. Psychology, 2(07), 760

Chan, F. R., \& Aziz, I. (2020). Motivasi Atlet Pencak Silat Pusat Pendidikan Latihan Pelajar (Pplp) Sumbar. Jurnal Patriot, 2(1), 120-128.

De Meester, A., Aelterman, N., Cardon, G., De Bourdeaudhuij, I., \& Haerens, L. (2014). Extracurricular school-based sports as a motivating vehicle for sports participation in youth: a cross-sectional study. International journal of behavioral nutrition and physical activity, 11(1), 48.

Donie, D., Lesmana, H. S., \& Hermanzoni, H. (2018). Personal trainer sebuah peluang karir. Performa, 3(01), 7-7.

FAHMI AFANDI, A. F. R. I. Z. A. L., \& KHAMIDI, A. (2018). MOTIVASI ATLET MENGIKUTI SSB PUTERA BUANA FC KU 16 LAMONGAN. Jurnal Prestasi Olahraga, 1(3).

Haryanto, J., \& Welis, W. (2019). Exercising Interent in the middle age group. Performa, 4(02), 214223.

Hermanzoni, H. Hubungan Motivasidan Koordinasi Mata Kaki dengan Kemampuan Sepaksia Atlet Sepaktakraw. Jurnal Patriot, 1(2), 565-577.

Hendri, F., Maidarman, M., Irawadi, \& Yenes, R. (2020). MOTIVASI ATLET ANGKAT BERAT. Jurnal Patriot, 2(3), 669-679.

Hudayah, N., \& Winarni, R. (2014). Pengaruh Kebijakan Pemerintah Indonesia Terhadap Kehidupan Etnis Tioghoha di Bidang Politik, Sosial Budaya, Dan Ekonomi Di Kabupaten Jember Dari Bidang Orde Lama sampai Zaman Reformasi Pada Tahun 1998-2012. Publika Budaya, 2(2), 19-31.

Iskandar, T. (2017). TINJAUAN MINAT BELAJAR MAHASISWA OLAHRAGA TERHADAP MATA KULIAH TENIS LAPANGAN DI UNIVERSITAS ISLAM 45 BEKASI.S Motion: Jurnal Riset Physical Education, 8(1), 27-39.

Julianda, R. T., \& Yendrizal, Y. (2018). Tinjauan Kondisi Fisik Pemain Kuansing Soccer School dI Teluk Kuantan. Jurnal JPDO, 1(1), 34-39.

Kuan, G., \& Roy, J. (2007). Goal profiles, mental tougness and its influence on performance outcomes among Wushu ahtlete. Journal of sports science \& medicine, 6(CSSI-2), 28.

Maidarman, M. (2020).Study Minat Mahasiswa Program Pendidikan Kepelatihan Olahraga Terhadap Senam Aerobik. Jurnal Patriot, 2(1), 278-290.

Maksum, A. 2012. Metoologi Penelitian dalam Olahraga. Universitas Negeri Surabaya Pers.

Ma, X., Sun, W., Lu, A., Ma, P., \& Jiang, C. (2017). The improvement of suspenses training for trunk muscle power in sanda athletes. Journal of Exercise Science \& Fitness, 15(2), 81-88.

Mardela, R., Yendrizal, Y., \& Yudi, A. A. (2019). MODIFIKASI PERMAINAN OLAHRAGA CRIKET UNTUK PEMULA. Performa Olahraga, 4(02), 206-213.

Milia, M. O., \& Aziz, I. (2020). Tinjauan Kemampuan Teknik Passing, dan Shooting Atlet Bolabasket Kub Nebular Siulak Kabupaten Kerinci. Jurnal Patriot, 2(2), 380-388.

Nastuti,D.H.H \& Sarwiyono, S.S. (2019). PERBANDINGAN PERILAKU HIDUP SEHAT SISWA SEKOLAH SWASTA di DAERAH KOTA dan PELOSOK KABUPATEN JEMBER. Jurnal Pendidikan Olahraga dan Kesehatan, 7(3). 
Novita, N. Evaluasi Prestasi Atlet Wushu Koni Kota Medan Tahun 2014. Jurnal Pengabdian Kepada Masyarakat, 21(82), 65-69.

Ridwan, M., \& Irawan, R. (2018). Validitas Dan Rehabilitas Tes Kondisi Fisik Atlet Sekolah Sepakbola (Ssb) Kota Padang "Battery Test Of Physical Conditioning". Performa, 3(02), 90-90

Setiawan, Y., Amra, F., \& Lesmana, H. S. (2018). Anaisis Tentang Cedera dalam Olahraga Belairi Taekwondo di Dojang UNP. Jurnal Stamina, 1(1), 401-414.

Setyawati, H. (2014).Strategi intervensi peningkatan rasa percaya diri melalui imagery training pada atlet wushu Jawa Tengah.Journal of Physical Education Health and Sport, 1(1), 4859.

Sin, T. H. (2016). Persiapan Mental Training Atlet AAm Menghadapi Pertandingan. Performa, 1(01), 61-73.

Soniawan, V., \& Irawan, R. (2018). Metode Bermain Berpegaruh Terhadap Kemampuan Long Passing Sepakbola. Performa, 3(01), 42-42.

Ulum, A. S. (2013). Pembinaan olahraga bela diri wushu dikota salatiga tahun 2013. ACTIVE: Journal of Physical Education, Sport, Health and Recreation, 2(10).

Undang-undang Republik Indonesia Nomor 3 Tahun 2005.Tentang Sistem Keolahragaan Nasional.Jakarta: Diperbanyak oleh Biro Humas dan Hukum Kementrian Pemuda dan Olahraga Republik Indonesia.

Van Heerden, C. H. (2014). The relationships between motivation type and sport participation among students in a South African context. Journal of Physical Education and Sport Management, 5(6), 66-71.

Wahyudi, W., \& Donie, D. (2019). Motivasi Berprestasi atlet sepakboa Jordus FC Kota Batusangkar. Jurnal JPDO, 2(1), 126-130. 